\title{
Effects Of Women's Seductive Dressing On Men's Behaviour And Judgement: A Study In Selected Universities In Ghana
}

\author{
Joycelyn Anku \\ Department of Fashion Design and Textiles Education, \\ University of Education, Winneba (Kumasi Campus), Ghana \\ Daniel Kwabena Danso \\ Department of Fashion Design and Textiles Education, \\ University of Education, Winneba (Kumasi Campus), Ghana \\ Jonathan E.T. Kuwornu-Adjaottor \\ Department of Religious Studies, \\ Kwame Nkrumah University of Science and Technology, Kumasi, Ghana
}

\begin{abstract}
Fashion, nowadays among others, has ostensibly been a defining factor of class differentiation among university students. Most students, particularly the females, struggle daily to meet up to these standards. Whereas modesty, courtesy, virtue and chastity among others are the terms which characterised the dressing of parents in a decade ago, modernity seems to have swept all these away and recast them in new relative meanings. In the light of this the study sought to find out the effects of women's suggestive dressing on men's behaviour and judgement. The study adopted survey as a research design. The study population involved students from University of Education, Winneba (Kumasi campus), Kwame Nkrumah University of Science and Technology, University of Ghana, Ghana Telecommunication University College and University of Development Studies. A sample size of 250 students was considered for the study. The constituents were made up of 125 females whereas the males were 125. Stratified sampling technique was used to group the population into sub strata. However, simple random sampling was used to select the five (5) universities. The study used questionnaire as the data collection instruments. The study found that there are different attires worn by female students on university campuses. Aside these varieties of dresses lay the motives for which female students wear them that culminates into the different attitudes men put up towards them. That is to say, most male students get tempted to lust after female students by their dressings. This affinity has the possibility of leading to promiscuous lifestyle on campuses. Based on this conclusions were made and recommendations included the issue that there should be institution of control measures on the university campuses to help monitor and direct females students to dress well.
\end{abstract}

Keywords: suggestive dressing, seductive dressing, modesty, decency, dress code

\section{INTRODUCTION}

The principle of dress code in tertiary schools is apparently to promote and embrace important values such as cleanliness, neatness, modesty, decency and appropriateness in dressing which reflect initial dignity and sobriety through which students as well as staff and faculty represent the professional status of their respective disciplines (Odeleye, 2000). Thus, many schools in Ghana like Takoradi Polytechnic have gone ahead to pronounce a well circulated dress code guidelines, which state among others that "Students are expected to be decently dressed on all occasions. In addition, dressing that will unduly expose vital parts of the body shall not be 
tolerated' (Ho Polytechnic Students Handbook, 2015:49). Wearing of tight, strapless and revealing clothes, or clothes whose lengths are above the knees are considered to be unsuitable on many campuses. Some departments and schools have further prescribed special clothing for certain occasions and lecture activities.

Dress code, according to Pauly (2008), is a set of rules, as in a school, indicating the approved manner of dress. However, campuses of higher institutions today have fostered a climate for the display of seductive wears especially by females. For instance, those who had visited the campuses of institutions of higher learning in recent times had wondered whether they were in an academic community or an enclave of fashion fair, owing to the provocative and seductive ways in which most of the students, particularly females clothed themselves to the lecture rooms. Anecdotal observation of the hallways of many higher institutions today reveals that students have pushed dress code to the limit. There are halter-tops and bare midriff, thigh underwear peeking above ultra low-cut jeans, and bright-coloured bras shining through sheer shirts.

On many campuses today, teachers and school authorities are now reduced to being the clothes police; a lot of time and energy that could have been spent on teaching is spent monitoring whether or not students keep to the order of the dress code battles. This problem is observed to be greater among the females and it is sweeping through developed and developing societies thus destroying further still the efforts to control immorality among the youthful population (Kayode, 2005). Consequent upon this, it is pertinent to note that certain countries have made some forms of improper dress strictly forbidden in their territories, because they have recognized that "proper dressing is necessary for the moral health of the nation".

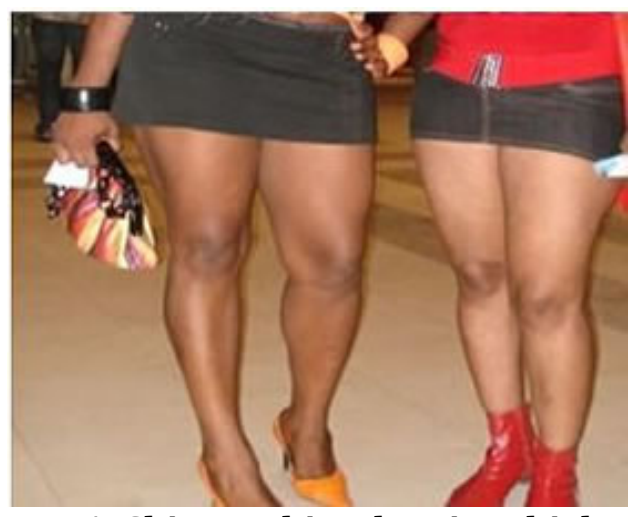

Figure 1: Skimpy skirt showing thigh of women Source: www.opera.com.gh/communities/student/indecent/dressing

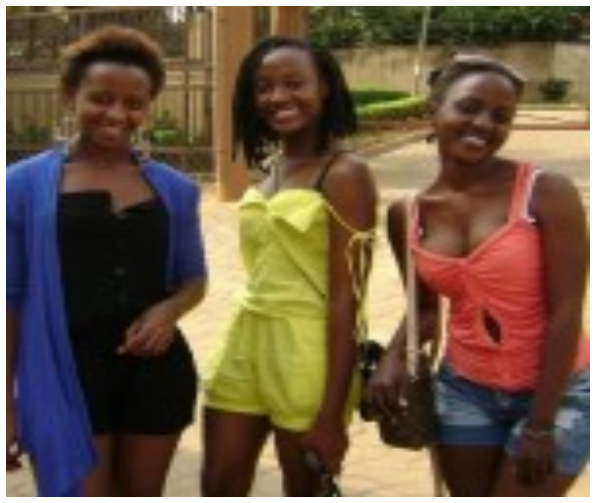

Figure 2: Dressing indicating erotic parts

\section{LITERATURE REVIEW}

\section{Uses of seductive (suggestive) women's dressing on university campuses}

What is seductive dressing? Seductive dressing, also called suggestive dressing, can be described as the improper way of dressing or the generally unaccepted way of dressing which exposes vital parts of the human body to reminiscent a thought already planned. That is, inappropriate and provocative ways of dressing relative to specific societies or cultures. According to Oyeleye (2013), suggestive dressing means the deliberate exposure of one's body to the public to attract an attention.

This practice violates the acceptable norms and values of the society. Adeboye (2012) defined suggestive dressing as the wearing of clothes that are not appropriate for a particular occasion or situation. Egwim (2010), referred to suggestive dressing as the attitude of someone, male or 
female that dresses to show off parts of the body such as the breasts, buttocks or even the underwear, particularly those of the ladies that need to be covered, to draw attention. This habit is found among all ages in the society but it is prevalent among youths. As vividly portrayed by Omede (2011:p):

What the girls call skirts that they wear is just "one inch" longer than their pants. When they put on such dresses, they struggle to sit down, find difficulty in climbing machines [motorcycles], cross gutters as well as pick anything from the ground. Apart from the skimpy and tight fitting nature of these dresses, they are again transparent; revealing certain parts of the bodies that under normal dressing patterns ought to be hidden away from the glare of people. In the case of boys, their pattern of dress ... makes them to look so dirty and very unattractive with unkempt hairs and dirty jeans having pockets of holes deliberately created around the knees and the lower part of the trousers allowed to flow on the ground because they go through their heals into their legs as socks. The waist of their trousers are lowered and fastened tightly at the middle of the two bottom lobes to reveal their boxers (pants). And when they are walking, they drag their legs and one of their hands particularly, the left one, cupping their invisible scrotum as if they will fall to the ground if not supported.

Every culture has its dressing code that may vary according to cultures. Despite this variation, one thing is certain that every culture has an acceptable dress code. So every dress code that deviates from the one acceptable to the community especially as it affects the set moral standards or judgment of the community is termed suggestive. The terms 'decency' and 'indecency' have so much to do with morality of the individual person and as judged by others. A dress is, therefore, said to be suggestive when it has provocative or stimulating influence on almost all those that happen to view it on the user. Egwim (2010) referred to suggestive dressing in a more specific term as the attitude of someone, male or female that dresses to show-off parts of the body such as the breasts, buttocks or even the underwear particularly those of the ladies that need to be covered.

This exposure is obviously a deliberate act to look sensuous, tantalizing and stimulating so as to draw the attention of the opposite sex and is more prevalent among singles (unmarried women and men). This form of dressing is provocative (Olori, 2003), improper and unacceptable. These dress patterns are morally offensive and reveals the high rate of moral decadence in the society of our time.

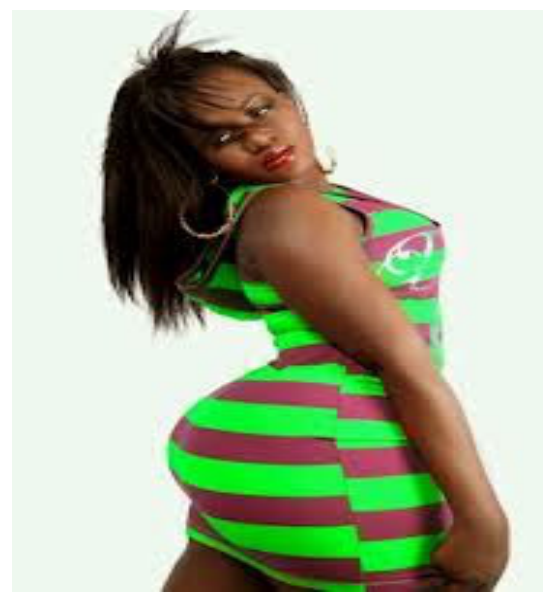

Figure 3: Straight dress showing hipped buttock

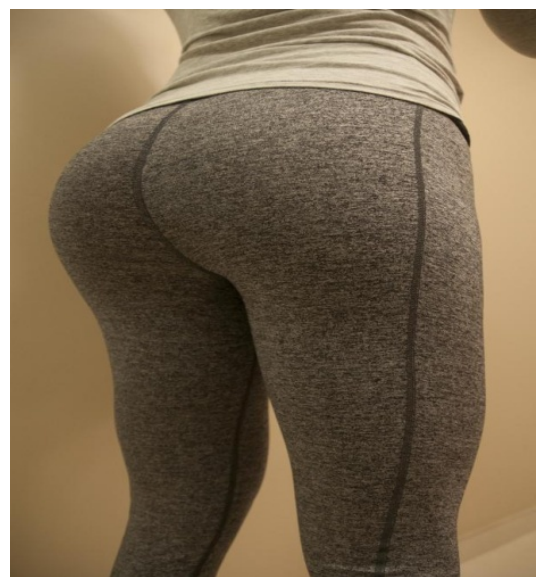

Figure 4: Skinny dress showcasing buttocks

\section{Men's perception of women's dressing}

Women and men differ in their perceptions of sexual intent of the opposite sex. For example, men are more likely than women to perceive social interaction between two individuals of the 
opposite sex in sexual term, and specifically, men tend to misinterpret the sexual interest of women based on their clothing. Abbey, Cozzarelli, Mclaughlin, and Harnish (1987) found that men were more likely than women to interpret a low-cut top, shorts, tight jeans, or no bra as indicator of sexual receptiveness.

Abbey et al (1987) reported that female targets who wore revealing clothing were rated by men as more sexy and seductive than women wearing non-revealing clothing. Koukounas and Letch (2001) reported that an actress who wore more revealing clothing was perceived by male observers as having more sexual intent than did the female observers. These latter studies seem to show that men misinterpret women's sexual intent according to their clothing appearance. However, these studies used photographs of women wearing or not wearing sexually evocative clothing, and men were instructed to rate the women's sexual intent with the help of a scale. Thus, the effect of women's suggestive clothing on men's behaviour in more ecological conditions still remains in question.

Men's spontaneous approach or behaviour toward women was measured and shortly afterwards the men were also asked to evaluate their chance to have a date with the female confederate and to have sex with her on the first date. It was expected that men would be significantly faster in approaching women with suggestive clothing, and would rate both the probability of having a date, and having sex on the first date, higher for women with suggestive clothing (Koukounas and Letch, 2001).

\section{Impact of female dressing on men's sexuality}

Jeffreys (2005) writes about beauty practices that females engage in, such as wearing make-up and hair removal, and how such habits can be interpreted as harmful and oppressive. She writes that:

Though women in the west sometimes say that they choose to engage in beauty practices for their own sake, or for other women and not for men, men benefit in several ways. They gain the advantage of having their superior sex class status marked out, and the satisfaction of being reminded of their superior status every time they look at a woman. They also gain the advantage of being sexually stimulated by "beautiful" women. These advantages can be summed up in the understanding that women are expected to both "complement" and "compliment" men. Women complement men by being the "opposite" and subordinate sex. Women compliment men by being prepared to make an effort to adorn themselves for men's sexual excitement. Thus men can feel both defined in manhood and flattered by women's exertions and, if the women are wearing high heels for instance, pain endured for their delight. (Jefferys, 2005:p)

The difference in gender responses to sexual appeals was researched by Dahl and Sengupta (2008). They found that on average, men react more positively to sexual appeals, which is a result of their open minded views on sex in general. The authors also discovered that the majority of women had a negative view on sexual appeals, which is a result of them having a more conservative upbringing because of pressures from their parents and institutions (Dahl and Sengupta, 2008). 


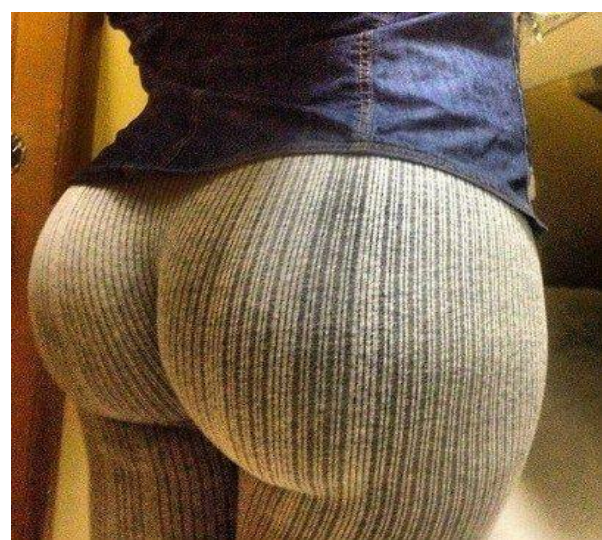

Figure 5: Dressing portraying sensual area

Physically, attractiveness is another factor for sexual harassment. Evolutionary Psychology posits that physical attraction in human is related directly to sexual selection. This is why humans have viewed certain features as attractive because these features are evident in healthy individuals (Fink and Penton-Voak, 2002). Researchers also show that males are more influenced by looks. Sprecher, Sullivan, and Hatfield (1994) found males to value the physical attractiveness of the opposite sex. Even though there are advantages of being beautiful and attractive, Hatfield and Sprecher (1986) reported that there is also an ugly truth about beauty. Those exceptionally attractive individuals are prone to unwelcome sexual advances or resentment from persons of the same sex.

It is without doubt that women and men differ in their sexuality and perceptions of sexual intent of the opposite sex. For example, men are more likely than women to perceive social interaction between two individuals of the opposite sex in sexual terms (Abbey, McDuffie and McAuslan, 1996), and specifically, men tend to misinterpret the sexual interest of women based on their clothing. They observed in their study that men were more likely than women to interpret a low-cut top, shorts, tight jeans, or no bra as indicator of sexual receptiveness.

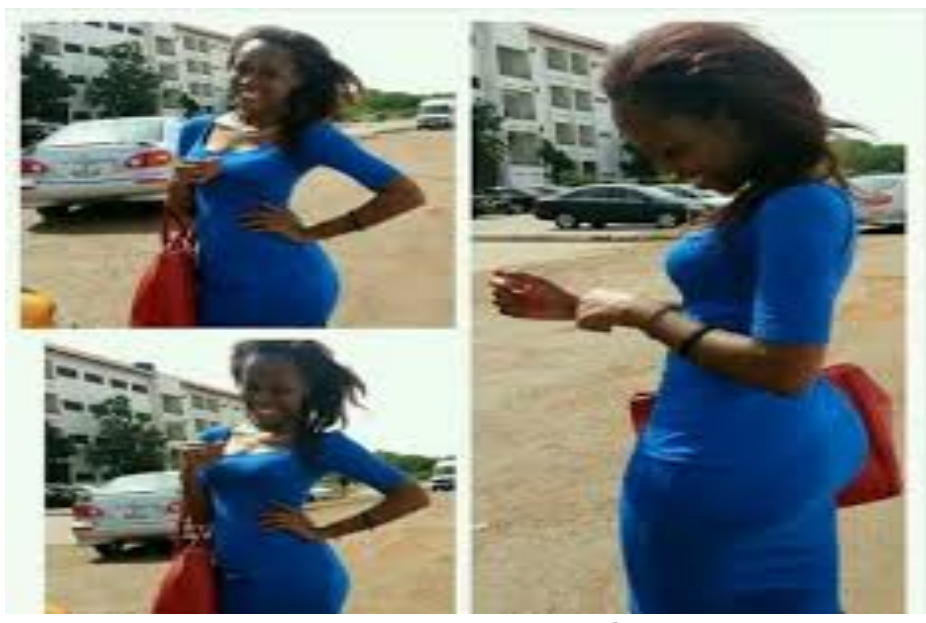

Figure 6: Suggestive dress

\section{Modesty verses immodesty}

In a largely traditional society where mainstream values are conveyed through beliefs, rules and structure, fashion, dressing and dress patterns form part of these values. Also, our universities have come to represent places where Western and traditional fashion frequently interact. In the process of interaction, students from diverse backgrounds come together and express their dress sense in varying modes and forms; engendering varying opinions and policies from the articulate public, school administrators, visitors, lecturers, nonteaching staff, 
parents and students on what students should wear on campus (Anderson and Bushman, 2001). Fashion trends and clothing patterns by students in tertiary institutions have thus become part of sources of concern to stakeholders in the educational sector. One of the ways some institutions are trying to arrest this situation is through the introduction of dress codes for both male and female students. This dress code policy is gradually becoming widespread within the universities and it is often questioned whether the free will of students at this level need to be curtailed.

It is commonly said that practically everyday, there are complaints about the provocative and suggestive dressing of students, most especially the female students. The complaints are usually about female students wearing skimpy, tight fitting and transparent outfits that expose vital parts of their body to lectures and other social gatherings in and outside campus. By wearing dirty jeans with pockets of holes deliberately created around the knees and lower parts of the trousers and the waist of their trousers lowered at the middle of their two bottom lobes, revealing their pant (underwear); piercing of any part of the body and tattooing on part of their body, some of the male students are also adjudged guilty of suggestive dressing in different ways than that of the females (Gbadegbe and Quashie, 2013).

According to Gregston (2014) although some school females may fully understand the need for modesty, but because of peer pressure, they are challenged to "fit in" to a culture that doesn't exactly affirm the values they know to be true; thus these females are torn between doing what is acceptable by their peer group so as to "fit in" and doing what is taught them by their families and the church. The definition of modesty has changed for them, not so much because of the lack of values taught by parents, but because of the overwhelming exposure given to seductive lifestyles. Furthermore, Gregston (2014) blames teenage females' seductive dressing on the culture which has become so pervasive resulting in today's teens being shaped by a world of sexual innuendoes where outward packaging and presentation is very important. While dressing seductively may just be a fad that soon passes, but at that particular time teens would be engaged in playing out a role on the stage of adolescence. This fad can be a challenge for parents to manage, since the internet, coupled with books, television, music, videos and movies have all inundated the youth with seductive images and inappropriate suggestions.

Highly sexualised lifestyles are touted as normal, so female face extreme social pressure to look and act seductively as well. Parents have to make sure that they impress to the girl child that modesty is an important part of their family values and an area they would not allow to be compromised, no matter what the current culture or fad says. This is affirmed by Gregston's quote from Martin Luther's saying “...have(ing) righteous principles in the first place...they will not fail to perform virtuous actions".

Jamaican's view on modesty dressing affirmed by observations from the visitors: Deb, Shala and Marie, and many others who had made several trips to Jamaica, stressed the importance of being culturally correct and to dress conservatively considering that local women wore skirts and blouses or dresses; thus, tight and revealing clothing, and parading around in shorts especially in restaurants or in the countryside (except on the beach) was not advisable. This was believed to encourage and attract propositions from men and at the same time invite glares and ridicule from local women. Further advice from Monique (1997) suggested being moderate in dressing and more covered up for less attraction of unwanted attention. Special reference was made to women in Kingston who were noted for their pride in wearing dresses and suit-dresses mostly to visit, and suits for going to work; thus, wearing of jeans in those instances would not be acceptable resulting in locals looking at the individual as a 'bad girl from downtown' therefore its important and advisable to be moderate in dressing. 


\section{How people evaluate women's dressing}

Studies have examined how people evaluate women based on how much of their bodies they reveal or conceal (Duits \& van Zoonen, 2006; Lennon, Lennon \& Johnson, 1996; Lynch, 2007). Particularly lacking are studies that ask respondents about their personal meanings of dress, although there are some exceptions (Guy \& Banim, 2003; Holland, 2004; Woodward, 2007).

The meaning of women's clothing vacillates between two opposing raisons d'être: the need to be covered and modest and the need to be uncovered, immodest and objectified (Sterling, 1995). Sterling wrote that types of dress project different archetypes: "sexy, professional, virginal, chic" (p. 89). For example, androgynous clothing can be a way to distance oneself from overt sexuality (Arnold, 2001). A long skirt could be considered both feminine and very modest, whereas a mini-skirt might be considered both feminine and immodest. Lynch, (2007) who studied flashing behaviour on a college campus, argued that men tend to sexually objectify women and may focus on specific parts of a woman's body, as opposed to looking at women as whole individuals.

Lynch went on to say that men also may view sex as a conquest, which implies that young women who are present at particular events on campus and/or exposing their bodies are viewed as willing participants even if they are not actually willing, which is similar to arguments made by Lennon (1993). Harvey (2007) suggested that women's sense of identity has been affected by a male dominated society.

Women have displayed their bodies because it has been desired by men, but, at the same time, many of the diatribes against immodesty also have come from men (Harvey). Duits and van Zoonen (2006) wrote that girls' bodies function as carriers for much wider discussions about decency and feminism. The authors explained that the female body is seen as passive, which can keep young women from defining their own actions. People make moral judgements about women based on how much of their bodies are exposed (Arnold, 2001), and standing out too much can be considered problematic if people perceive it as drawing too much attention of a sexual nature. An article published in Dutch explained that G-strings were blamed for gang rapes that took place in France (Duits \& van Zoonen, 2006). Lennon (1993) described a kidnapping and sexual assault case in which the jurors referred to the clothing that the victim wore. The authors explained that the jurors' statements exemplify the stereotype that: Women invite their own rapes, sexual assaults, and sexual harassment by the manner in which they dress. Women's characters are more likely to be judged based on how revealing or concealing their clothings are (Ribeiro, 2003).

Sterling's (1995) study examined semiotic and evidentiary meanings of women's clothing in rape trials, but the statements she made about clothing are relevant in general. She pointed out that: "Clothing covers the body. The act of wearing clothing draws attention to what the clothing covers as well as what it reveals. People who believe that women's bodies are irresistibly tempting to men argue that a woman is responsible not only for herself but for man's sexual behaviour too: if a man succumbs to sexual temptation in thought or deed it is considered her fault for dressing provocatively (Entwistle, 2000). Yet, almost anything can be construed as sexually provocative, which makes it easier to place the blame on the victim rather than the perpetrator.

\section{Decency}

While certain types of clothing may represent different archetypes within a culture, they do not have an objective meaning, and their significance will be interpreted differently depending on the individual characteristics of the observer (Lennon, 1993). For example, one person might 
interpret a woman's outfit as being sexually explicit, while another person might think that she was dressed appropriately for a night out. The terms "decency" and "modesty" are framed in everyday usage as concepts that are defined clearly and generally agreed upon, when in reality there is no clear definition of what it means to be decent in modern society (Duits \& van Zoonen, 2006).

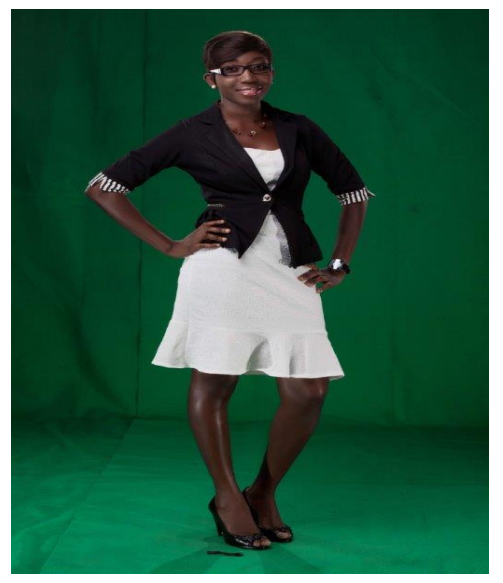

Figure 7: Dressing not exposing seductive parts

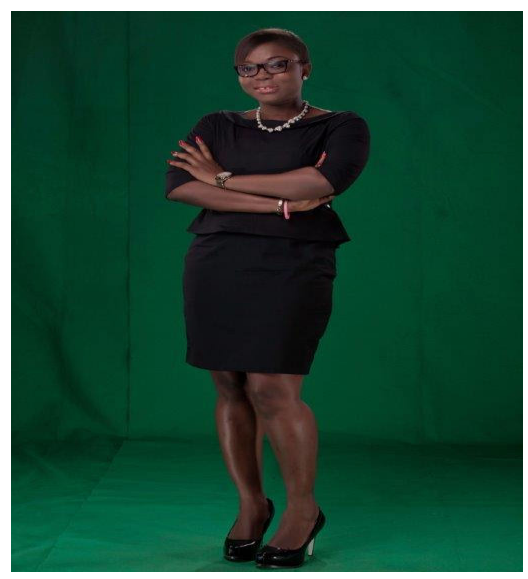

Figure 8: Attire covering seductive parts

\section{Context of wearing clothes and modesty}

Beliefs relate to an individual's perspective on modesty, but context is also important. The idea of context ranges from the cultural context to more specific circumstances of wearing. Sterling (1995) described how she alters what she is wearing based on where she is. She compared workplace and cocktail attire and explained that, if she wore workplace attire to a cocktail party, she would be dressed too conservatively, but if she wore cocktail attire to work she would feel too revealed. Lynch (2007) explained that context plays a role in what is considered provocative and gave the example of a young woman wearing a bikini top to the beach versus to a bar.

At the beach, this top would be considered appropriate, while at a bar it would be considered provocative. Hendrie (2009) research suggested that it was the percentage of skin showing that related to attracting attention from males in a night club, rather than which parts of the body were exposed. The line between immodest and modest occurred at about $40 \%$ body exposure. Hendrie, Mannion, and Geofrey (2009) pointed out that other research has found that night clubs are dark, crowded and very noisy, which means that physical display is more important than it would be in other situations. They suggested that these are the reasons that exposure garners more male attention. Thus, going to a club in conservative clothing might make it more difficult to interact with others given that it is very difficult to talk, and dress may be considered to express personality more than it might in other settings. In Lynch's study a participant stated that girls at homecoming were supposed to dress in clothing that was very revealing, which as Lynch pointed out, suggests that provocative dress may be associated with revealing the female form (Lynch, 2007).

\section{METHODOLOGY}

A descriptive survey research approach was adopted for this study. A survey research design was used because of it being fact finding in nature. Survey research, according to Leedy and Ormrod (2005: 183), 'involves acquiring information about one or more groups of people perhaps about their characteristics, opinions, attitudes, or previous experiences - by asking them questions and tabulating their answers.' The ultimate goal, in their view, is to learn about a large population by surveying a sample of the population. 
A sample size of 250 students was used for the study. The constituents were made up of 25 female students and 25 male students each from five public universities in Ghana; namely University of Education, Winneba (Kumasi Campus), Kwame Nkrumah University of Science and Technology, University of Ghana, Ghana Telecommunication University College, and University of Development Studies. Stratified random sampling technique was adopted for the selection of the respondents from the universities for the study.

Data were gathered with the use of two sets of questionnaire; thus, one set for male students and the other set for female students. The questions were of the Likert-like with the scale from 'strongly agree' to strongly disagree'.

Data collected, was preceded by the data processing and interpretation of the data as the next procedure. The answers of the participants were tabulated and the frequency, distribution table of values, and percentages of the answers determined.

\section{Response Rate}

\subsection{RESULTS AND DISCUSSIONS}

The data was analysed using 200 questionnaires received from the respondents out of 250 distributed by the researcher. This, however, constitutes $80.0 \%$ of the entire questionnaires administered.

\section{Types of dresses female students wear on university campuses}

Table 4.1 indicates the different types of dressing outfits female students wear on university campuses in Ghana, gathered from the female student respondents. They are arranged based on the level or rate of usage of the outfits by the female university students. Thus, they vary from trousers and shirt, skinny trousers with top, miniskirt with blouse, trousers and blouse, transparent outer garment, long skirts with blouse, net/lace structured, low seat trouser (I am aware) and high opened slit. Statistically, 67 respondents constituting $67.0 \%$ and 28 of them representing $28.0 \%$ strongly agreed and agreed, respectively, that trousers and shirt as outfit is a type of dress they wear on campus. Meanwhile 1 respondent, constituting $1.0 \%$ and 2 respondents forming $2.0 \%$ disagreed and strongly disagreed, respectively, that trousers and shirt is a type of dresses they wear on campus. On the other hand 2 respondents representing $2.0 \%$ remained on trousers and shirt as a type of dresses they wear on campus.

In answering the question on skinny trousers with top as a type of outfit female students wear on campuses, 21 respondents constituting $21.0 \%$ and 72 respondents forming $72.0 \%$ strongly agreed and agreed respectively to the statement. On the contrary, 4 respondents representing $4.0 \%$ and 3 of them constituting 3.0\% disagreed and strongly disagreed respectively to the statement that skinny trousers with top is a type of outfit they wear on campus. Moreover, on miniskirt with blouse as a type of outfit female students wear on various campuses in Ghana, 21 respondents representing $21.0 \%$ strongly agreed and 63 of them representing $63.0 \%$ agreed to the statement, whereas 8 respondents constituting $8.0 \%$ disagreed and 2 respondents representing $2.0 \%$ strongly disagreed that miniskirt with blouse is a type of outfit they wear on campus. However, the remaining 6 of them constituting $6.0 \%$ remained neutral on the issue that miniskirts with blouse is a type of outfit they wear on campus.

Concerning the use of trousers with blouse as a type of outfit female students wear on campuses, 23 respondents forming $23.0 \%$ and 68 respondents representing $68.0 \%$ strongly agreed and agreed respectively to the statement. Conversely, 2 respondents representing $2.0 \%$ and 7 of them constituting $7.0 \%$ disagreed and strongly disagreed to the statement. In addition, on the issue that transparent outer garment is a type of dress female students wear on campus, 
14 respondents constituting $14.0 \%$ and 41 of them representing $41.0 \%$ strongly agreed and agreed respectively to the statement. On the other hand, 27 respondents representing $27.0 \%$ and 18 respondents representing $18.0 \%$ disagreed and strongly disagreed that transparent outer garment is a type of dress female students wear on campuses.

On the issue that long skirt with blouse is a type of dress female students wear on university campuses, 18 respondents constituting 18.0\% strongly agreed and 11 of them representing $11.0 \%$ agreed to the statement. Meanwhile 54 of them representing 54.0\% and 14 respondents constituting $14.0 \%$ disagreed and strongly disagreed that long skirts with blouse is a type of dress they wear on campuses. On the other hand, the remaining 3 of them forming $3.0 \%$ remained neutral on long skirt with blouse as a type of dress they wear on the campuses. Moreover, on net/lace structure as a type of dress female students wears on campuses, 3 respondents forming $3.0 \%$ and 7 of them representing $7.0 \%$ strongly agreed and agreed respectively to the statement. However, 27 respondents forming $27.0 \%$ and 63 respondents representing 63.0\% disagreed and strongly disagreed that net/lace structure is a type of dress they use on their campuses.

On whether low seat trouser (I am aware) is a type of dress female students wear on the campuses, 4 respondents representing $4.0 \%$ and 9 of them constituting $9.0 \%$ strongly agreed and agreed respectively to the statement. On the contrary, 42 respondents constituting $42.0 \%$ and 39 respondents representing 39.0\% disagreed and strongly disagreed respectively that low seat trouser (I am aware) is a type of dress they wear on their campuses. On the other hand, 3 respondents representing 3.0\% remained neutral on the issue that low seat trousers (I am aware) is a type of dress female students wear on campuses. Concerning the issue that high opened slit is a type of dress female students wear on campus, 5 respondents representing $5.0 \%$ and 2 of them constituting $2.0 \%$ strongly agreed and agreed to the statement, respectively. Conversely, 35 respondents representing $35.0 \%$ disagreed and 58 of them constituting $58.0 \%$ strongly disagreed that high opened slit is a type of dress they wear on campus.

The results of the study indicate that trousers with shirt top is a type of outfit female students wear most on the various campuses, followed by skinny trousers with top. In addition, female students do not wear low seat trousers (I am aware) and high opened slit on the various campuses.

Table 4.1: Types of dresses female students wear

\begin{tabular}{lllllll}
\hline Type of dresses & \multicolumn{3}{c}{ Responses } & Total \\
\cline { 2 - 5 } & 1=SA & $\mathbf{2 = A}$ & $\mathbf{3 = N}$ & $\mathbf{4 = D}$ & $\mathbf{5 = S D}$ & \\
\cline { 2 - 5 } Trousers and shirt & $67(67.0 \%)$ & $28(28.0 \%)$ & $2(2.0 \%)$ & $1(1.0 \%)$ & $2(2.0 \%)$ & $100(100.0 \%)$ \\
Skinny trousers with top & $21(21.0 \%)$ & $72(72.0 \%)$ & $0(0.0 \%)$ & $4(4.0 \%)$ & $3(3.0 \%)$ & $100(100.0 \%)$ \\
Miniskirts with blouse & $21(21.0 \%)$ & $63(63.0 \%)$ & $6(6.0 \%)$ & $8(8.0 \%)$ & $2(2.0 \%)$ & $100(100.0 \%)$ \\
Trousers and blouse & $23(23.0 \%)$ & $68(68.0 \%)$ & $0(0.0 \%)$ & $2(2.0 \%)$ & $7(7.0 \%)$ & $100(100.0 \%)$ \\
Transparent outer & $14(14.0 \%)$ & $41(41.0 \%)$ & $0(0.0 \%)$ & $27(27.0 \%)$ & $18(18.0 \%)$ & $100(100.0 \%)$ \\
garment & & & & & & \\
Long skirts with blouse & $18(18.0 \%)$ & $11(11.0 \%)$ & $3(3.0 \%)$ & $54(54.0 \%)$ & $14(14.0 \%)$ & $100(100.0 \%)$ \\
Net/lace structured & $3(3.0 \%)$ & $7(7.0 \%)$ & $0(0.0 \%)$ & $27(27.0 \%)$ & $63(63.0 \%)$ & $100(100.0 \%)$ \\
Low seat trouser (I am & $4(4.0 \%)$ & $9(9.0 \%)$ & $3(3.0 \%)$ & $42(42.0 \%)$ & $39(39.0 \%)$ & $100(100.0 \%)$ \\
aware) & & & & & & \\
High opened slit & $5(5.0 \%)$ & $2(2.0 \%)$ & $0(0.0 \%)$ & $35(35.0 \%)$ & $58(58.0 \%)$ & $100(100.0 \%)$ \\
\hline
\end{tabular}

Key: SA=Strongly Agree, A=Agree, $\mathrm{N}=$ Neutral, $\mathrm{D}=\mathrm{Disagree}, \mathrm{SD}=$ Strongly Disagree Source: Field Study, 2016 


\section{Men's perception of female students' dressing on university campuses}

As regards the views of males on the university campuses concerning the dressings of female students on the campuses, diverse perceptions were gathered by the researchers. From data gathered, it is deduced that a greater number of male students have the perception of female students' dressings: are always sexually tempting, are very provocative to look at, their dressings are decent and modest, they have always hated their choice of dresses and style of dressing and their dresses draws attention to women to propose to them.

From the responses, as shown in Table 4.2, it can be read that $34 \%$ respondents strongly perceive that female students' seductive dressing on university campuses are always sexually tempting to the male gender. On this point 37\% respondents also agree to the fact that, the dressings of female students are always sexually tempting. On the opposite side 14\% respondents also disagree that dressings of female students are always sexually tempting while $15 \%$ respondents also strongly disagree. From the analysis, it can be deduced that, despite the disagreements, majority of the respondents perceive that dressings of female students are always sexually tempting. To this end, it can be construed that, the male gender are tempted by the dressings of the female students which has the likelihood of influencing promiscuous lifestyle among the male students all because Sprecher (1994) found males to value the physical attractiveness of the opposite sex.

On a different perception, $37 \%$ respondents strongly agreed that female dresses on campuses are very tight and very provocative to look at. Also 39\% respondents constituting a greater number agreed to the idea that female attires are very provocative to behold. It can be read that $4 \%$ respondents denoting the minority remained neutral while $11 \%$ respondents disagreed same as $9 \%$ respondents strongly disagree on the grounds that the tight dresses of female students are not provocative to look at. Irrespective of the contrary view of minority of the respondents, it can be construed that majority of them perceive the dressings of female students on campuses to be very tight and provocative. The outcome can be reconciled with what Koukounas and Letch (2001) reported that wearing revealing clothing is perceived by male observers as having more sexual intent and provocation. Therefore, it stands to reason that the male students are likely to lust after ladies to promote irresponsible sexual relationship with the tendencies to contribute to unwanted pregnancies and abortions.

From the responses indicated in Table 4.2 , it can be read that $17 \%$ respondents strongly perceive the dressings of female students to be decent and modest while $21 \%$ respondents also agree aside $12 \%$ respondents who remain neutral. However, $20 \%$ respondents disagree while $30 \%$ of the respondents representing the highest number also strongly disagreed to the statement. As indicated by the analysis, it can be deduced that majority of the respondents strongly disagreed to the idea that the female students dressings on campuses are decent and modest. This concludes the facts most of the respondents abhors the dressings of campus lifestyles of female students.

For $30 \%$ respondents, as indicated in Table 4.2 , it can be read that they strongly perceive those who dress seductively to be prostitutes while 29\% respondents also agree though $20 \%$ remained neutral to this. However, $21 \%$ respondents disagreed. The outcome of the responses brings forth the fact that, most female students who put on seductive dresses are perceived to be prostitutes on campuses. Upon this it can be suggested that, the most female students who dress seductively are bound to suffer respect from their peers.

From the standpoint of $21 \%$ respondents, as presented in Table 4.2 , they strongly perceive the seductive attires female students put on to be too old-fashioned same as $23 \%$ respondents who 
also agree aside the neutrality of $15 \%$ of the respondents. On the other hand, $21 \%$ respondents disagree while $20 \%$ respondents also strongly disagree to the fact that the dressings of female students on campuses are too old-fashioned. The responses make it evident that though most respondents adore the dressing to be modern, but few majority sees that to be old-fashioned.

Table 4.2 Men's perception of females seductive dressing

\begin{tabular}{lcccccc}
\hline Statement & \multicolumn{5}{c}{ Responses } & Total \\
\cline { 2 - 5 } & $\mathbf{1}=\mathbf{S A}$ & $\mathbf{2}=\mathbf{A}$ & $\mathbf{3}=\mathbf{N}$ & $\mathbf{4}=\mathbf{D}$ & $\mathbf{5 = S D}$ & \\
\cline { 2 - 5 } $\begin{array}{l}\text { The dressing of female } \\
\text { students are always sexually } \\
\text { tempting }\end{array}$ & $34(34 \%)$ & $37(37 \%)$ & $0(0 \%)$ & $14(14 \%)$ & $15(15 \%)$ & $100(100.0 \%)$ \\
$\begin{array}{l}\text { Their tight dresses are very } \\
\text { provocative to look at }\end{array}$ & $37(37 \%)$ & $39(39 \%)$ & $4(4 \%)$ & $11(11 \%)$ & $9(9 \%)$ & $100(100.0 \%)$ \\
$\begin{array}{l}\text { I think their dressing is } \\
\text { decent and modest }\end{array}$ & $17(17 \%)$ & $21(21 \%)$ & $12(12 \%)$ & $20(20 \%)$ & $30(30 \%)$ & $100(100.0 \%)$ \\
$\begin{array}{l}\text { I have always perceived those } \\
\text { who dress seductively to be } \\
\text { prostitutes }\end{array}$ & $30(30 \%)$ & $29(29 \%)$ & $20(20 \%)$ & $21(21 \%)$ & $0(0 \%)$ & $100(100.0 \%)$ \\
$\begin{array}{l}\text { I have perceived their } \\
\text { dressings to be too old- } \\
\text { fashioned }\end{array}$ & $21(21 \%)$ & $23(23 \%)$ & $15(15 \%)$ & $21(21 \%)$ & $20(20 \%)$ & $100(100.0 \%)$ \\
\hline
\end{tabular}

Key: SA=Strongly Agree, A=Agree, N=Neutral, $D=$ Disagree, $S D=$ Strongly Disagree

Source: Field Study, 2016

\section{Effects of the use of seductive dressing on university campuses}

The following, as presented in Table 4.3, refer to the different opinions espoused by both female and male students as effects of seductive female dressings on campuses. It was postulated that: female dressing provokes sexual harassment and rape, female dressing inflames indiscriminate sex behaviour, female dressing incites sexual thoughts in men, men tend to sexually objectify female students and female dressing incite lust in men.

In expansion, Table 4.3, illustrates that as part of the views regarding the effects of seductive dressing on campuses, $32 \%$ respondents strongly agree that such dressings provoke sexual harassment and rape. In like sense, 38\% respondents constituting the highest number also agree to the same view. Notwithstanding these responses, $20 \%$ respondents disagreed while $10 \%$ respondents also strongly agree to the fact that female dressing provokes sexual harassment and rape. Summing both responses, it can be said that, majority of the respondents are in agreement with the argument that female dressings on university campuses provoke sexual harassment and rape.

'Female dressing inflames indiscriminate sex behaviour', as statement in Table 4.3 is what 30\% respondents strongly agree to as the effect of seductive dressing put up by female students on campuses. In the same way 31\% respondents, designating the highest number of respondents, also agree that seductive dressing influences indiscriminate sex behaviour on campuses but $10 \%$ respondents have no idea to share on this issue. In a differing response $19 \%$ respondents disagree to the issue in question while $10 \%$ respondents also strongly disagree to same point. It is undeniable from the outcome of the responses that, seductive dressings on campuses cause indiscriminate sexual behavior among students because majority of the responses prove that. Upon this, it can be said that sexual immorality on campuses can be attributed to the influence of seductive appearance of female students in dressing. 
Furthermore, as per the effects of seductive dressing on campuses, 32\% respondents strongly believe that female dressing incites sexual thoughts in men while $47 \%$ respondents also agree though $21 \%$ respondents have no ideas to share. The massive responses demonstrate that seductive attires cause men to focus on sexual thoughts. Based on this finding it will not be out of order to say that students, especially males, will likely become addicted to watching pornographies just to satisfy their sexual thoughts.

From Table 4.3, it can be read that $30 \%$ respondents strongly agree to the fact that men tend to sexually objectify female students when they dress seductively. It is the same way that $32 \%$ respondents also agreed but $12 \%$ respondents remained neutral. However, it can be read that $16 \%$ respondents disagree while $10 \%$ respondents also strongly disagree that men do not sexually objectify female students because of their seductive dresses. From inference, it can be realised that seductive dressing causes male students to disrespect the female students.

Table 4.3 shows that $24 \%$ respondents strongly agree that female dressing incite lust in men so does 23\% respondents also agree but 11\% respondents remained neutral. Besides the preceding $20 \%$ respondents have dissenting responses same as $22 \%$ respondents also disagree strongly to the fact that seductive dressing incite lust in men on the campuses.

Table 4.3: Effects of the use of seductive dressing

\begin{tabular}{|c|c|c|c|c|c|c|}
\hline \multirow[t]{2}{*}{ Statement } & \multicolumn{5}{|c|}{ Responses } & \multirow[t]{2}{*}{ Total } \\
\hline & $1=S A$ & $2=A$ & $3=N$ & $4=D$ & $5=S D$ & \\
\hline $\begin{array}{l}\text { Female dressing provokes } \\
\text { sexual harassment and rape }\end{array}$ & $64(32 \%)$ & $76(38 \%)$ & $40(20 \%)$ & $20(10 \%)$ & $0(0 \%)$ & $\begin{array}{c}200(100.0 \% \\
)\end{array}$ \\
\hline $\begin{array}{l}\text { Female dressing inflames } \\
\text { indiscriminate sex behaviour }\end{array}$ & $60(30 \%)$ & $62(31 \%)$ & $20(10 \%)$ & $38(19 \%)$ & $20(10 \%)$ & $200(100.0 \%$ \\
\hline $\begin{array}{l}\text { Female dressing incites sexual } \\
\text { thoughts in men }\end{array}$ & $64(32 \%)$ & $94(47 \%)$ & $42(21 \%)$ & $0(0 \%)$ & $0(0 \%)$ & $\begin{array}{c}200(100.0 \% \\
)\end{array}$ \\
\hline $\begin{array}{l}\text { Men tend to sexually objectify } \\
\text { women }\end{array}$ & $60(30 \%)$ & $64(32 \%)$ & $24(12 \%)$ & $32(16 \%)$ & $20(10 \%)$ & $\begin{array}{c}200(100.0 \% \\
)\end{array}$ \\
\hline $\begin{array}{l}\text { Female dressing incite lust in } \\
\text { men }\end{array}$ & $48(24 \%)$ & $46(23 \%)$ & $22(11 \%)$ & $40(20 \%)$ & $44(22 \%)$ & $\begin{array}{c}200(100.0 \% \\
)\end{array}$ \\
\hline
\end{tabular}

Key: SA=Strongly Agree, A=Agree, N=Neutral, D=Disagree, SD=Strongly Disagree

Source: Field Study, 2016

\section{Ways of ensuring that appropriate female dressing patterns are used on university campuses}

In considering ways of ensuring that appropriate female dressing patterns are used on university campuses, the following represent the measure proffered by the respondents: there should be national policy on campus dressing, cultural values should be taught in schools, punitive measures must be put in place, religion must be promoted on campuses, and students must be allowed to dress as they want (Table 4.4).

As a means of ensuring that female students dress appropriately on campuses $43 \%$ of the respondents, constituting the highest number of respondents, strongly agreed that there should be national policy on campus dressing. This response is agreed to by $36 \%$ respondents while $7 \%$ respondents remained neutral. Aside the foregoing, $14 \%$ of the respondents disagreed to the application of national policy to control dress codes of female students on campuses. Based on the major responses, it can be put forward that, the institution of national policies will help control the mode of dressing on campuses. In support of this, Freeburg, Workman, \& Lentz-Hee, (2004) suggested that, it is high time the universities established rules to help govern students' dress codes and appearance. This, according to Nwagwu (2000), is 
because there is need for students to be aided in clarifying their values and modifying their attitudes so as to be able to make rational decisions in socially, relevant acceptable way.

Moreover, 32\% respondents strongly agreed while $29 \%$ respondents also agreed that the cultural values should be taught in schools while $15 \%$ respondents have no ideas to share on this issue. Regardless of the above-mentioned responses $11 \%$ respondents disagreed while $13 \%$ also strongly disagreed to the institution of the teaching of cultural values in schools. The responses prove that the allowing of cultural values to be taught in university campuses is in the right direction to ameliorate the supposed poor dressing of female students on campuses. The outcome arises out of the major decisions of the respondents. Upon this, it can be put up that, the lack of dresscode is giving way for poor dresscodes on campuses. Therefore, teaching cultural values in schools has become relevant because Gregston (2014) believes that most female students, though may fully understand the need for modesty, but because of peer pressure, they are challenged to "fit in" to a culture that does not exactly affirm the values they know to be true; thus these female are torn between doing what is acceptable by their peer group and what is taught them by their families and the church. On this point one can conjecture that teaching female students the cultural values in schools will reposition them so far as the need for proper dressing is eminent.

Per the responses specified in Table 4.4, it can be read that most of the respondents representing $32 \%$ strongly agreed that punitive measures must be put in place while $43 \%$ respondents also agree that punitive measures established will help curb improper dressing in schools. While $20 \%$ respondents remained neutral in this respect $5 \%$ respondents have dissenting views to the extent that instituting punitive measures will not be a panacea to improper dressings on campuses. From the analysis of responses, it can be inferred that, putting in place punitive measures is necessary according to the majority of responses. On this note, it can be construed that universities need good measures that are corrective in nature to streamline the dressing of female students on campuses.

In addition, from the perspective of $23 \%$ respondents, they strongly believe that there is the need to promote religious principles on campuses to maintain good appearance in dressing. In the same line, another $23 \%$ of the respondents also agreed to the above-mentioned issue. Though 5\% respondents have no idea on this approach, 24\% respondents disagreed and $26 \%$ respondents also strongly disagreed to this mode of ensuring appropriate dressing on campuses.

It can be read from the Table 4.4 that, as for $12 \%$ of the respondents, it is their strong believe that female students must be allowed to dress as they want while $23 \%$ respondents also agree. On the contrary $28 \%$ respondents disagree just as $37 \%$ respondents denoting the highest number of respondents strongly disagree to the statement. As indicated from the analysis, though some respondents believe female students should be allowed to dress as they want the majority oppose this. 
Table 4.4: Ensuring appropriate female dressing

\begin{tabular}{|c|c|c|c|c|c|c|}
\hline \multirow{2}{*}{ Statement } & \multicolumn{5}{|c|}{ Responses } & \multirow[t]{2}{*}{ Total } \\
\hline & $1=S A$ & $2=A$ & $3=N$ & $4=D$ & $5=S D$ & \\
\hline $\begin{array}{l}\text { There should be national } \\
\text { policy on campus dressing }\end{array}$ & $86(43 \%)$ & $72(36 \%)$ & $14(7 \%)$ & $28(14 \%)$ & $0(0 \%)$ & $200(100.0 \%)$ \\
\hline $\begin{array}{l}\text { Cultural values should be } \\
\text { taught in schools }\end{array}$ & $64(32 \%)$ & $58(29 \%)$ & $30(15 \%)$ & $22(11 \%)$ & $26(13 \%)$ & $200(100.0 \%)$ \\
\hline $\begin{array}{l}\text { Punitive measures must in } \\
\text { place }\end{array}$ & $64(32 \%)$ & $86(43 \%)$ & $40(20 \%)$ & $10(5 \%)$ & $0(0 \%)$ & $200(100.0 \%)$ \\
\hline $\begin{array}{l}\text { Religion must be promoted } \\
\text { on campuses }\end{array}$ & $46(23 \%)$ & $44(22 \%)$ & $10(5 \%)$ & $48(24 \%)$ & $52(26 \%)$ & $200(100.0 \%)$ \\
\hline $\begin{array}{l}\text { Students must be allowed } \\
\text { to dress as they want }\end{array}$ & $24(12 \%)$ & $46(23 \%)$ & $0(0 \%)$ & $56(28 \%)$ & $74(37 \%)$ & $200(100.0 \%)$ \\
\hline
\end{tabular}

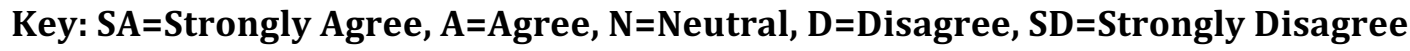
Source: Field Study, 2016

\section{Conclusions}

\section{CONCLUSIONS AND RECOMMENDATIONS}

Apparently there are different attires worn by female students on university campuses. The study concludes that attires are worn to shows ones level of class in the society and even among their peers. It is to say that most students dress in some attire to indicate that they have the means to afford their choice of attires.

Mostly, according to the study, aside the penchant of female students to look attractive and exquisite in appearance, most of them dress to attract the male counterpart. In this way they put on seductive dresses having men in mind apparently to attract them. It stands to reason that the male students are likely to lust after the females thereby encouraging irresponsible sexual relationship that has the tendencies to contribute to sexual harassment, rape with their attendant unwanted pregnancies.

It can be concluded that, most male students get tempted to lust after female students by their dressings. This affinity has the possibility of bringing about promiscuous lifestyles on campuses. However, such seductive dresses are deemed old-fashioned according to study. It is also concluded that most of the respondents in the study abhor seductive dressings of female students on university campuses. In all, the institution of control measures was noted to be relevant on the university campuses so as monitor and direct female students to dress well.

\section{Recommendations}

The following are recommendations made based on the outcome of the study:

\section{Monitoring}

Female students' modes of dressing should constantly be monitored on university campuses to check the seductiveness of them. This will help curtail any amorous and promiscuous lifestyles.

\section{Guidance and Counselling}

The motives why female students prefer putting on seductive attires should be studied critically. This will enable the guidance and counselling units on university campuses to give proper advice and counselling on the modes of dressing on the university campuses.

\section{Policy on campus dressing}

There should be policies to govern students' way of life in general and females dressing in particularly. With this the female students will know what and how to dress and appear on campuses. This will help to avoid tempting the sexuality of the male gender. 


\section{Punitive measures}

Instituting disciplinary measures on university campuses will help guide and scare female students from wearing seductive dresses.

\section{Attitude of male students}

The male students should be counseled well to focus on their academic duties and avoid being lustful of the female students. This will help curb promiscuity and possible loss of concentration on their studies.

\section{References}

Abbey, A., Ross, L. T., McDuffie, D., \&McAuslan, P. (1996). Alcohol and dating risk factors for sexual assault among college women. Psychology of women quarterly, 20(1), 147- 169.

Abbey, A., Cozzarelli, C., McLaughlin, K., \& Harnish, R. J. (1987). The effects of clothing and dyad sex composition on perceptions of sexual intent: do women and men evaluate these cues differently? Journal of Applied Social Psychology, 12, 108-126.

Adeboye (2012). Indecent dressing. 3 blogspot.com/2012/ Retrieved November 30, 2015

Anderson, C. A., \& Bushman, B. J. (2001). Effects of violent video games on aggressive behaviour, aggressive cognition, aggressive affect, physiological arousal, and pro-social behavior: A meta-analytic review of the scientific literature. Psychological Science, 12, 353-359.

Arnold, R. (2001). Fashion, desire and anxiety: Image and morality in the 20th century. New Brunswick: Rutgers University Press.

Dahl, D.W. \& Sengupta, J. (2008). Gender-related reactions to gratuitous sex appeals in advertising. Journal of Consumer Psychology. 18, pp.62-78.

Duits, L., \& van Zoonen, L. (2006). Headscarves and porno-chic: Disciplining girls' bodies in the European multicultural society. European Journal of Women's Studies, 13(2), 103-117.

Egwim, C. (2010). Indecent Dressing Among Youths. http://www.es/networld.com/webpages/features Retrieved November 10, 2015.

Entwistle, J. (2000). 'Fashion and the Fleshy Body: Dress as Embodied Practice', Fashion Theory: The Journal of Dress, Body \& Culture, 4(3): 323-347.

Fink, B. \& Penton-Voak, I. (2002). Evolutional Psychology of Facial Attractiveness. Current Direction in Psychological Sciences, 11, 154-158.

Freeburg, E.W., Workman, J. E., \& Lentz-Hee, E. S. (2004). Rationale for students' dress code: a review of students' handbook

Gbadegbe, S. R. \& Quashie, M, (2013) “The Impact of Indecent Dressing on the Academic Performance of Students in Tertiary Institutions, a Case Study of Ho Polytechnic in Ghana" Journal of Education and Practice www.iiste.org ISSN 2222-1735 (Paper) ISSN 2222-288X (Online) Vol.4, No.18, 2013 166) Retrieved 15 October, 2015

Gregston, M. (2014). Modesty in a seductive culture. Parenting Today's Teens. http://www.heartlightministries. org/blogs Retrieved November 12, 2015.

Harvey, J. (2007) Showing and hiding: Equivocation in the relations of body and dress.Fashion Theory, 11(1), 8594.

Hatfield, E. \& Sprecher, S. (1986). Measuring passionate love in intimate relationship. Journal of adolescence, 9 , 383 - 410. Retrieved November 10, 2015.

Hendrie, C. A., Mannion, H. D., \& Godfrey, G. K. (2009) Evidence to suggest nightclubsfunction as human sexual display grounds. Behaviour, 146, 1331-1348.

Ho Polytechnic (2015). Students Handbook. www.hopoly.edu.gh/students handbook. Retrieved November 12, 2015

Holland, S. (2004). Alternative femininities: Body, age and identity. Oxford: Berg.Hamilton, A., Madison, J., Jay, J., \& Goldman, L. (2008). The federalist papers. Oxford University Press.

Jeffreys, S. (2005) Beauty and Misogyny: Harmful Cultural Practices in the West. London: Routledge Print. 
Kayode, 0. (2005). Functional properties of native, physically and chemically modified breadfruit (Artocarpusartilis) starch." Industrial Crops and Products 21, no. 3: 343-351.

Koukounas, E., \& Letch, N. M. (2001). Psychological correlates of perception of sexual intent in woman. The Journal of Social Psychology, 141, 443-456.

Leedy, P. D. \& Ormrod, J. E. (2005). Practical Research: Planning and Design (6 $6^{\text {th }}$ ed.). New Jersey: Pearson Prentice Hall.

Lynch, A. (2007). Expanding the definition of provocative dress: An examination of female flashing behavior on a college campus. Clothing and Textiles Research Journal, 25(2), 184-201

Monique, (1997). What should we wear? www.journeywoman.com/ccc/ccc-j.htmlnbhvreddi, 2010. Impact of media on teenagers.http://www.studymode.com/essays/Impact-Of-Media-On-Teeenagers-395072.html

Odeleye, A. D. (2000). Psychological correlates of contemporary clothing behaviour of Nigerian undergraduate students. Unpublished doctoral thesis, Obafemi Awolowo University, Ile-Ife, Nigeria.

Olori, T. (2003). Culture-Nigeria: “Indecent” dressing banned on the campus. Retrieved June, 10, 2015,http://wwwipsnews.net/africa/interna.asp?idnews.

Omede. J. (2011). Indecent Dressing on Campuses of Higher Institutions of Learning in Nigeria: Implications for Counseling" Journal of Emerging Trends in Educational Research and Policy Studies(JETERAPS) 2 (4): $228-233$. Scholarlink Research Institute Journals, (ISSN: 2141-6990)

Oyeleye A. (2013). Indecent Dressing: A Social Malady. file; ///F:/ www. Nation htm Retrieved August 30, 2015.

Pauly, J. M. (2008).Compressed sensing MRI.Signal Processing Magazine, IEEE, 25(2), 72-82.

Ribeiro, A. (2003). Dress and morality (2nd ed.). Oxford: Berg.

Sprecher, S., Sullivan, Q., \& Hatfield, E. (1994). Mate selection preferences: gender differences examined in a national sample. Journal of personality and social psychology, 66(6), 1074.

Sterling, A. C. (1995). Undressing the victim: The intersection of evidentiary and semiotic meanings of women's clothing in rape trials. Yale Journal of Law and Feminism, 7, 87-132.

Woodward, S. (2007). Why women wear what they wear. Oxford: Berg. 